\title{
Signaling network of dendritic cells in response to pathogens: a community-input supported knowledgebase
}

\author{
Sonali Patil ${ }^{1 \dagger}$, Hanna Pincas ${ }^{1 \dagger}$, Jeremy Seto ${ }^{1}$, German Nudelman, Irina Nudelman², Stuart C Sealfon ${ }^{*}$
}

\begin{abstract}
Background: Dendritic cells are antigen-presenting cells that play an essential role in linking the innate and adaptive immune systems. Much research has focused on the signaling pathways triggered upon infection of dendritic cells by various pathogens. The high level of activity in the field makes it desirable to have a pathwaybased resource to access the information in the literature. Current pathway diagrams lack either comprehensiveness, or an open-access editorial interface. Hence, there is a need for a dependable, expertly curated knowledgebase that integrates this information into a map of signaling networks.

Description: We have built a detailed diagram of the dendritic cell signaling network, with the goal of providing researchers with a valuable resource and a facile method for community input. Network construction has relied on comprehensive review of the literature and regular updates. The diagram includes detailed depictions of pathways activated downstream of different pathogen recognition receptors such as Toll-like receptors, retinoic acidinducible gene--llike receptors, C-type lectin receptors and nucleotide-binding oligomerization domain-like receptors. Initially assembled using CellDesigner software, it provides an annotated graphical representation of interactions stored in Systems Biology Mark-up Language. The network, which comprises 249 nodes and 213 edges, has been web-published through the Biological Pathway Publisher software suite. Nodes are annotated with PubMed references and gene-related information, and linked to a public wiki, providing a discussion forum for updates and corrections. To gain more insight into regulatory patterns of dendritic cell signaling, we analyzed the network using graph-theory methods: bifan, feedforward and multi-input convergence motifs were enriched. This emphasis on activating control mechanisms is consonant with a network that subserves persistent and coordinated responses to pathogen detection.

Conclusions: This map represents a navigable aid for presenting a consensus view of the current knowledge on dendritic cell signaling that can be continuously improved through contributions of research community experts. Because the map is available in a machine readable format, it can be edited and may assist researchers in data analysis. Furthermore, the availability of a comprehensive knowledgebase might help further research in this area such as vaccine development. The dendritic cell signaling knowledgebase is accessible at http://tsb.mssm.edu/ pathwayPublisher/DC_pathway/DC_pathway_index.html.
\end{abstract}

\section{Background}

The innate immune system represents the first line of defense against attack by viral, bacterial, and parasitic infections. Dendritic cells (DCs), which are found in

\footnotetext{
* Correspondence: stuart.sealfon@mssm.edu

+ Contributed equally

'Center for Translational Systems Biology and Department of Neurology, Mount Sinai School of Medicine, New York, NY 10029, USA

Full list of author information is available at the end of the article
}

abundance in peripheral tissues such as skin, lung, and mucosal surfaces, act as a bridge between the innate and adaptive immune systems: recognition of a 'danger' signal initiates the maturation of DCs, which ultimately activate cells of the adaptive arm of the immune system, $B$ and T cells [1-3]. DCs express receptors that recognize and bind a large array of epitopes or antigens common to many bacterial or viral pathogens; once an antigen is recognized, it is internalized, processed, and

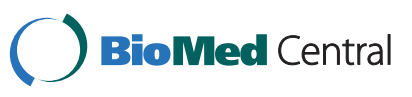

(c) 2010 Patil et al; licensee BioMed Central Ltd. This is an Open Access article distributed under the terms of the Creative Commons Attribution License (http://creativecommons.org/licenses/by/2.0), which permits unrestricted use, distribution, and reproduction in any medium, provided the original work is properly cited. 
presented at the cell surface in association with molecules of the major histocompatibility complex (MHC). DC maturation is characterized by up-regulation of the MHC molecules, production of cytokines, chemokines and co-stimulatory molecules, and migration of DCs to lymphoid tissues, i.e. the spleen and the lymph nodes (for review, see $[3,4]$ ). Research efforts have aimed at understanding the DC signaling and effector pathways that direct this cell's crucial role in immunity. A graphical representation of those signaling pathways as a biological system would provide an easily accessible, integrated view of the literature in this field to the scientific community.

DCs detect pathogens via pattern recognition receptors (PRRs), which recognize various molecular structures referred to as pathogen-associated molecular patterns (PAMPs), e.g. lipopolysaccharides, lipoteichoic acids, flagellin and nucleic acids. Membrane-associated PRRs, like the Toll-like receptors (TLRs) and C-type lectin receptors (CLRs) respond to extracellular pathogens, while cytosolic PRRs, including RIG-I-like receptors (RLRs) and NOD-like receptors (NLRs) sense intracellular pathogens [5-7]. Pathogen recognition activates an intracellular signaling cascade, which results in the expression of type I interferons (IFNs), as well as other inflammatory response genes. Secreted IFNs bind to cell surface receptors and activate the JAK-STAT pathway in an autocrine and paracrine fashion [8,9]. A resource that facilitates access to information on the molecular networks that underlie DC signaling responses to various pathogens would assist research on antibacterial and antiviral therapy. Furthermore, it might benefit the development of DC vaccines against cancers and autoimmune diseases, as manipulating DCs in vitro and rendering them responsive to tumor antigens may lead to tumor regression [10]. Traditional representations of molecular pathways may be found in reviews. A webbased pathway diagram complements these reviews by giving more direct access to continually updated literature information in a pathway format. Also a pathwaybased resource can be used directly for computational studies. SBML is a computer-readable format for representing models of biological processes [11]. Therefore, an optimal pathway diagram should focus on a whole biological system rather than a part of it, comply with a standard format, such as the Systems Biology Mark-up Language (SBML; http://sbml.org/), and be accessible to the community for updates and corrections.

Current databases of signaling networks of the innate immune response include free online resources such as the Kyoto Encyclopedia of Genes and Genomes (KEGG) Pathway database http://www.genome.jp/kegg/pathway. html[12], Reactome, which is a curated knowledgebase of biological pathways http://www.reactome.org/cgi-bin/
frontpage?DB=gk_current[13], Science's Signal Transduction Knowledge Environment (STKE; http://stke. sciencemag.org/cm/) biological pathways database, and Ingenuity Systems, a commercial subscription-based knowledgebase. The KEGG pathways do not integrate all PRRs, but rather depict each type of PRR-derived pathway separately and with little detail. Although Reactome is abundantly annotated and organism-specific, it does not provide cell-type specific information. STKE features 19 immunity-related pathways, the majority of which, however, have not been updated in recent years. Similar to Reactome, Ingenuity Systems offers a great diversity of annotations, including literature references from various biological models and many other database resources, yet it presents a fairly basic version of each signaling network and is not cell-type specific. In contrast, the group of Kitano [14] constructed a comprehensive map of TLRs and interleukin 1 receptor signaling networks based on published literature; the TLR pathway map, created in CellDesigner [15], is comprised of 652 species and 444 reactions and complies with SBML. However, it lacks a means for communitywide feedback, which would considerably help experts in the field to directly participate in the map update, and is not cell-type specific.

Based on a manual curation of the published literature, we have assembled an extensive and detailed map of the signaling pathways involved in DC response to pathogens, as described in human DCs and mouse models. The DC pathway map, which is web-accessible, includes the following annotations: a list of interactions, GeneIDs, PubMed IDs (PMIDs), along with summary notes. In order to provide a discussion forum for the community and an opportunity for direct feedback and contribution, we have linked the DC map to a public wiki. Thus, it should represent a valuable resource for the research community, and conceivably initiate a community-wide interactive process. Additionally, using computational methods we delineated the regulatory motifs that are present in the DC signaling network.

\section{Construction and content}

To summarize the complexity of the pathogen recognition response in DCs, we have developed a map of signaling events occurring in those cells upon viral and bacterial infection. This map was assembled in CellDesigner, a free process diagram editor for gene-regulatory and biochemical networks http://celldesigner.org/; it was then web-published using BioPP, a software suite which converts CellDesigner-SBML formatted pathways into a web-viewable format [16]. Hence, this knowledgebase is deposited into a public repository endowed with a pathway navigator, which facilitates browsing through the nodes and entities of the uploaded pathway. Each entity 
in the network is annotated with a complete list of interactions in which it participates, and PMIDs supporting those interactions (Figure 1). Entities are also linked to NCBI Entrez Gene pages and to their respective wiki pages. Furthermore, users may download the DC signaling pathway diagram from the BioPP website in an $\mathrm{xml}$ format, which allows them to edit and/or expand it in CellDesigner, based upon their own experimental data or knowledge.

At present, the DC signaling network consolidates manually curated information from 167 peer-reviewed journal articles. Target publications are mainly reports on human DCs and mouse models, as well as studies in heterologous expression systems. In particular, as the main interest of our research group is monocyte-derived DCs obtained from human blood donors, namely conventional DCs, we have not yet included plasmacytoid DCs in the knowledgebase. To avoid adding more visual complexity to the diagram, we have chosen not to depict response genes, but rather represent their respective
RNAs. For simplicity, transcription factors and other regulatory complexes are directly connected to the RNAs of the response genes they activate. Additionally, the molecular machinery required for the transportation of transcription factors from the cytoplasm to the nucleus and vice versa has been omitted. The network consists of 249 entities or nodes and 213 reactions or edges. Among the 118 protein species, 20 were classified as receptors and 2 as truncated proteins, the remainder being comprised of intracellular proteins as well as transcription factors. The reactions can be classified into 122 state transitions (which include catalysis reactions), 9 heterodimer associations, 4 dissociations, 36 transcriptional activations, 8 unknown transitions, 8 transport reactions, 21 inhibitions, and 4 translations.

\section{Main structural features of the map}

The DC signaling network (Figure 2) can be divided into four main pathways, each of which is activated by a different family of PRRs: the TLRs, CLRs, RLRs, and NLRs.

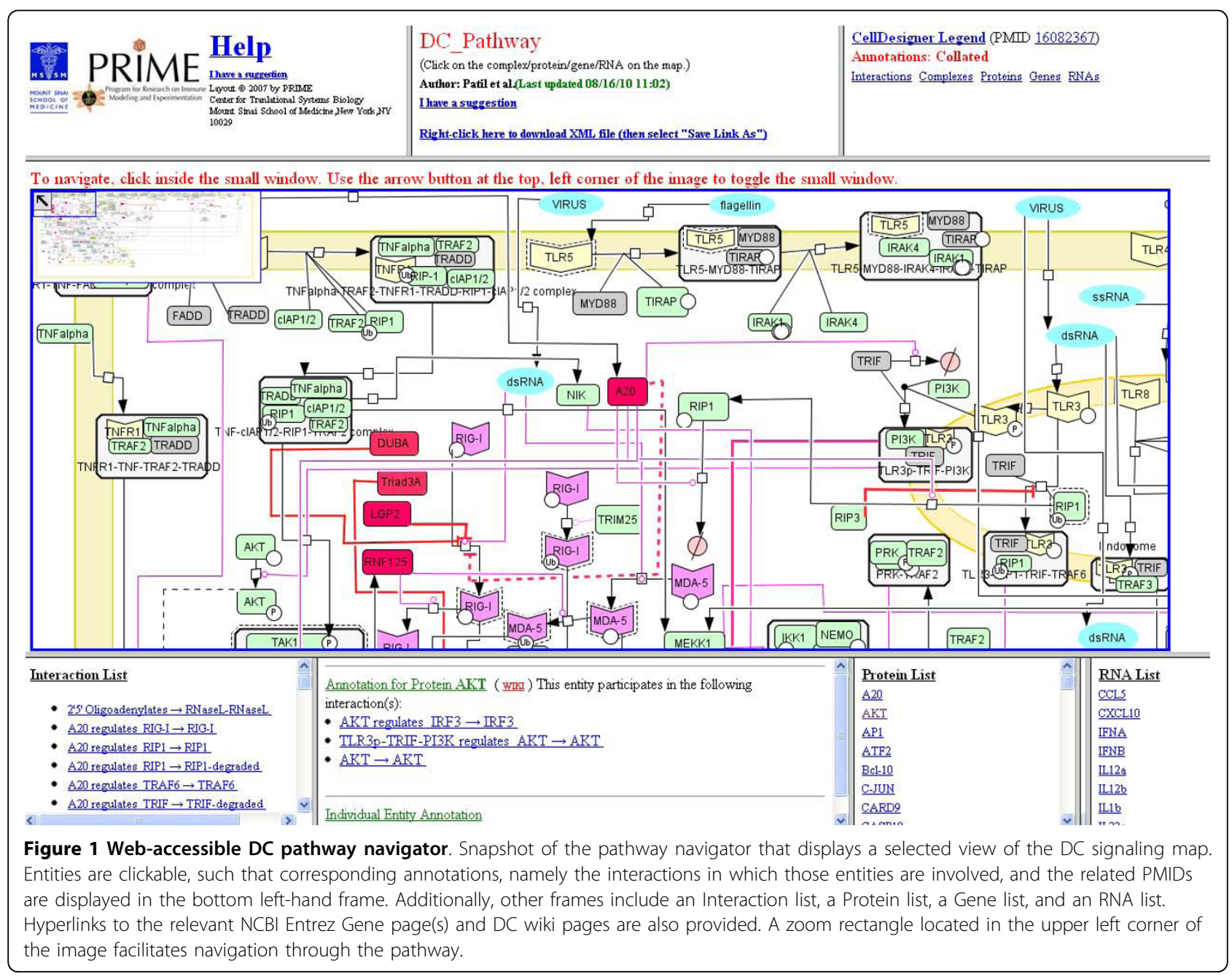




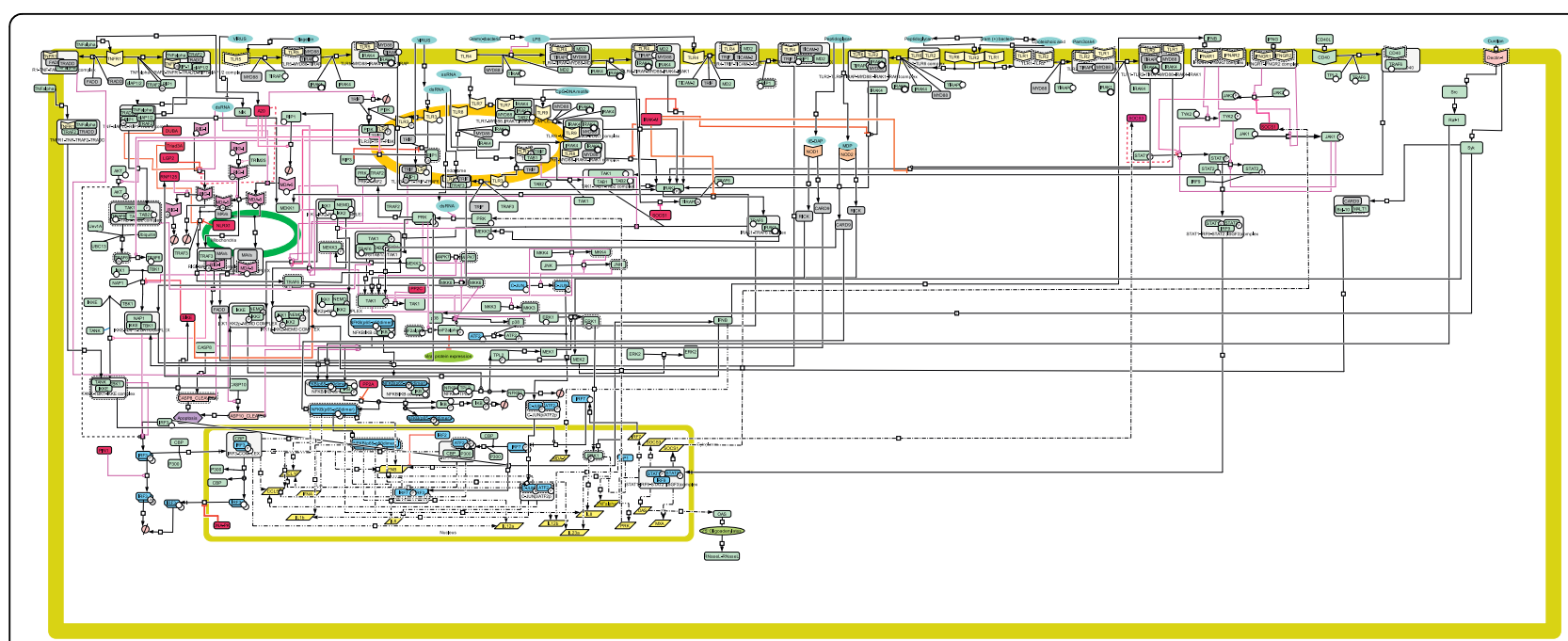

Figure 2 Snapshot of the DC signaling pathway map. This map was created using CellDesigner ver.4.0.1, ver.4.0. $\alpha$, and ver.4.1 $\mathrm{http} / / /$ celldesigner.org/. The main symbols used may slightly differ from those implemented by CellDesigner ver.4.0.1 and ver.4.0. $\alpha$, as indicated. Interactions are color-coded: black filled arrows, stimulatory reactions; red bar-headed lines, inhibitory reactions; black dashed and double-dotted lines, transcriptional activation reactions (instead of transcription reactions); pink round-headed lines, catalysis reactions; black filled arrows with a bar, transport reactions. The presence of a question mark signifies that, whether the reactions are direct or indirect, is unknown. Translation reactions are represented by dashed and single-dotted lines. Modification states of proteins, i.e. phosphorylation and ubiquitination, are symbolized by $\mathrm{P}$ and $\mathrm{Ub}$, respectively. Entities that are bordered with a dotted frame are considered in an active state. The following cellular compartments are illustrated on the diagram, as indicated: cytoplasm, endosome, mitochondria, and nucleus. The color-coding of entities was put together by us: pathogens and PAMPs in turquoise, TLRs in yellow, RLRs in purple, CLRs in pink, NLRs in orange, adaptors in grey, transcription factors in light blue, kinases in light green, and negative regulators in red. The map can be more easily viewed on the web at http://tsb.mssm.edu/pathwayPublisher/DC_pathway/DC_pathway_index.html.

Besides being initiated by different PRRs, these pathways involve distinct adaptors and lead to the expression of genes in response to individual microbes. Those genes encode inflammatory cytokines, such as interleukin-12 (IL-12, IL-6, IL-23), which are necessary to stimulate T cells (T helper cells Th1, Th2, Th17, or Tregs) for the adaptive immune response. Because $\mathrm{T}$ cell responses are beyond the scope of the DC signaling network, they were not illustrated on the DC map. Importantly, the pathways often share common downstream signaling molecules [17]. The pathway interconnectivity, which is illustrated on the DC map (Figure 2) and detailed further below, is presented in a more condensed form in Figure 3. Likewise, we describe diverse negative regulatory mechanisms employed by DCs to control their PRR responses to pathogens, and provide a basic depiction of those mechanisms in Figure 4.

There are 13 different members in the TLR family of proteins identified across mammalian species (TLR1-13). We omitted TLR10, which is not functional in mice, and TLR 12 and TLR13, which are lost in humans. TLRs recognize a wide variety of PAMPs ranging from lipids, lipoproteins, glucans to nucleic acids [18]. They are characterized by leucine rich repeats (LRRs) that mediate PAMP recognition and a cytoplasmic TIR domain that transmits the signal downstream via adaptor molecules.
The main adaptors include MyD88, TRIF, TRAM and TIRAP [19-24]. Individual TLRs mediate distinct responses by association with a different combination of adaptor molecules. Additionally, some TLR family members can form heterodimers that recognize specific microbial structures. For instance, TLR1 and TLR6 were shown to form heterodimers with TLR2: TLR1/2 heterodimers interact with bacterial triacyl lipopeptides, while TLR2/6 heterodimers recognize diacyl lipopeptides and lipoteichoic acid $[25,26]$. While nearly all TLRs recruit MyD88, TLR3 mediates its response merely through TRIF. The association of TLRs and MyD88 recruits members of the IL-1 receptor-associated kinase (IRAK) family. In turn, IRAK4 and IRAK1 activate transcription factors NF $\kappa \mathrm{B}$ and AP-1 through the canonical IKK complex and the MAPK pathway, respectively. NF $\kappa$ B consecutively stimulates the expression of inflammatory cytokine genes, including TNF $\alpha$, IL- 6 and IL-1 $\beta$ [3]. In contrast with MyD88, TRIF interacts with protein kinases IKKE and TBK1, which activate IRF3 and IRF7 $[20,27]$. Interestingly, TLR4 signals through both MyD88 and TRIF, leading to activation of $\mathrm{NF} \kappa \mathrm{B}$ and IRFs, respectively $[20,28]$.

The RLRs RIG-I and MDA5 activate NF $\kappa \mathrm{B}$ and IRF3 independently of TLRs. RIG-I interacts with either ssRNA or dsRNA through an RNA helicase domain, 


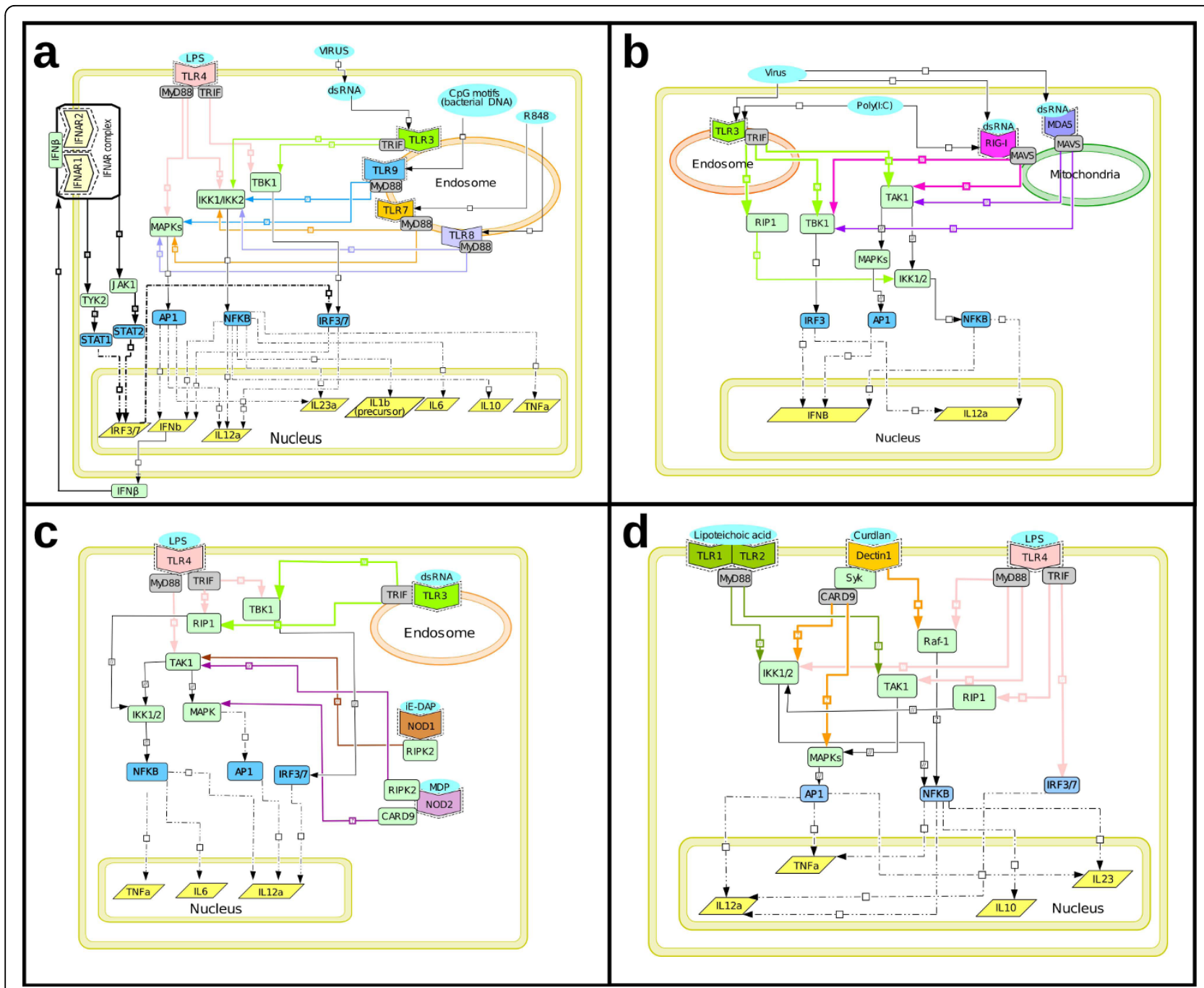

Figure 3 Cross talks between signaling pathways downstream of PRRs. (a) Cross talk between different TLRs. The diagram illustrates the cross talks between TLR3 and TLR 7-9, and between TLR4 and TLR7-9. For instance, TLR4 (in pink) and TLR7-9 (in yellow, light purple, and blue, respectively) signaling pathways converge at both IKKs and MAPKs. (b) Cross talk between TLR3 and RLRs (RIG-I and MDA5). (c) Cross talk between TLR4 and NLRs (NOD1 and NOD2). (d) Cross talks between TLRs and CLRs. The diagram illustrates the cross talks between TLR2 and Dectin-1, and between TLR4 and Dectin-1. Symbols: black or color-coded filled arrows, stimulatory reactions; black dashed and double-dotted lines, transcriptional activation reactions; black filled arrows with a bar, transport reactions. The presence of two forward slashes signifies that known stimulatory reactions (i.e. intermediate reactions) were omitted. PRR entities that are bordered with a dotted frame are considered in an active state.

and recruits adaptor MAVS via a CARD-CARD association $[29,30]$. MAVS stimulates IKKE/TBK1, which in turn activate IRF3 and IRF7. Consecutively, those IRF family members induce type I IFN response by activating IFN $\beta$ transcription $[20,31]$.

CLRs recognize carbohydrate structures present on bacterial or fungal pathogens (for review, see [32]). They are characterized by a carbohydrate recognition domain (CRD) involved in carbohydrate binding. Different CLRs, such as MR, Langerin, Dectin-1 and MGL, interact with different glucan structures. In our network diagram, we chose to depict the Dectin-1-dependent pathway in detail: Dectin- 1 binds fungal $\beta$-glucans and recruits SYK and CARD9, which leads to activation of $\mathrm{NF} \kappa \mathrm{B}$, and subsequent induction of inflammatory cytokines (for review, see [33]).

The NLR family of intracellular PRRs includes NOD1, NOD2, and NALP3. NOD1 and NOD2 recognize distinct motifs derived from the peptidoglycan bacterial cell wall, while NALP3 responds to multiple stimuli (for review, see [34]). NOD1 and NOD2 possess a CARD domain responsible for the signaling, whereas NALP3 has a pyrin domain instead (for review, see [35]). Both NOD1 and NOD2 recruit adaptor RICK, which activates TAK1. 


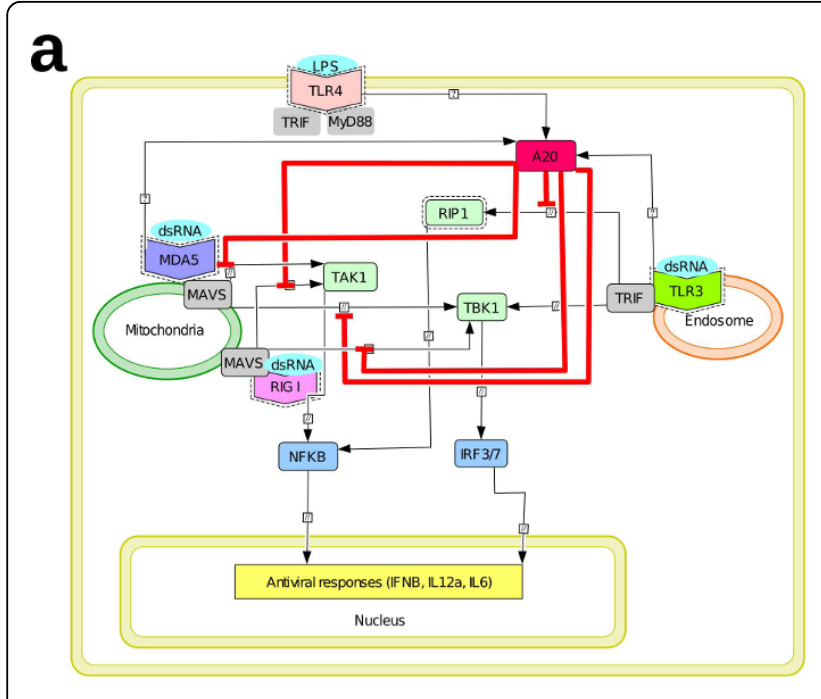

\section{b}

\section{C}

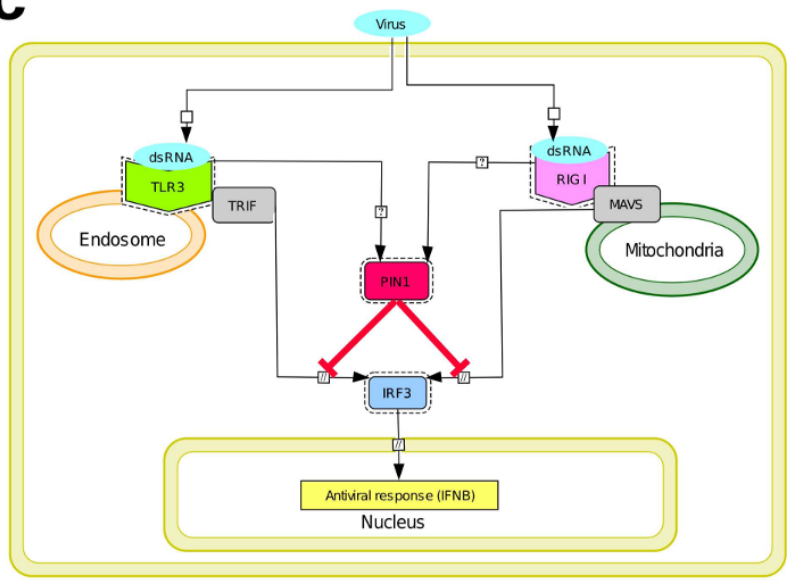

d

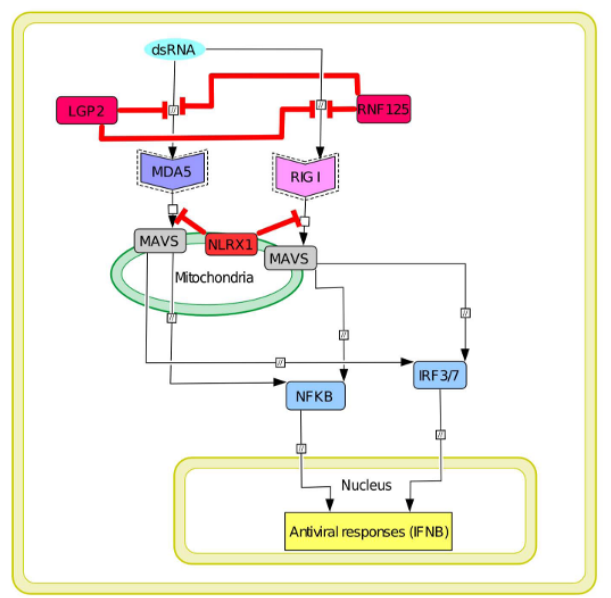

$\mathbf{e}$

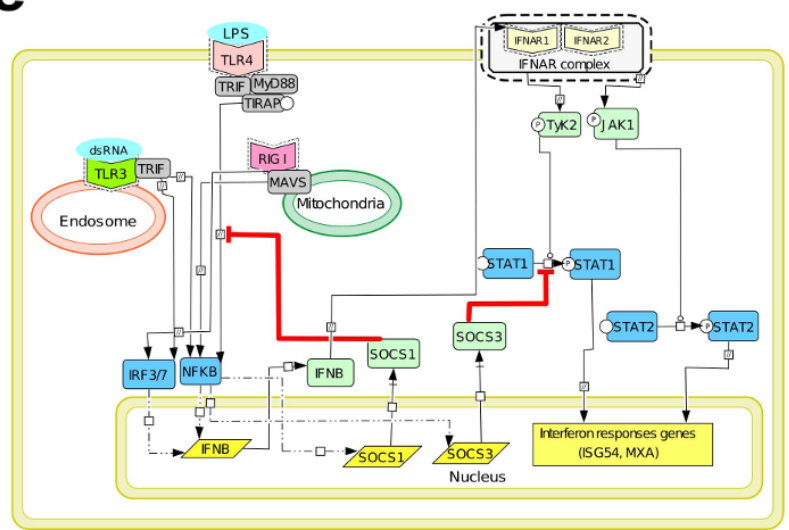

Figure 4 Negative regulations of PRR responses. (a) Negative regulation of TLR3-, RIG-I-, and MDA5-induced pathways by A20. (b) Negative regulation of RIG-I- and TLR3-induced pathways by SIKE. (c) Negative regulation of TLR3- and RIG-I-induced pathways by PIN1. (d) Negative regulation of MDA5 and RIG-I signaling by both RNF125 and NLRX1. (e) Negative regulation of JAK/STAT signaling by SOCS proteins, and of TLR4 signaling by SOCS1. In this diagram, transcriptional activation reactions were represented by black dashed and double-dotted lines, and protein phosphorylation was signified by $\mathrm{P}$. 
TAK1 activates the MAPK cascade and $\mathrm{NF} \kappa \mathrm{B}$, which in turn induce genes of the IL-1 family of inflammatory cytokines. In response to diverse stimuli such as bacterial RNA or endogenous danger signals (extracellular ATP, uric acid crystals), NALP3 forms an inflammasome. The NALP3 inflammasome contains NALP3, ASC, Cardinal, and Caspase-1, and leads to activation of Caspase- 1 and subsequent maturation of the pro-inflammatory cytokine IL-1 $\beta$ [36]. Here, we intentionally represented the NOD1- and NOD2-dependent pathways.

\section{Cross talk and synergy between the signaling pathways downstream of PRRs}

Multiple PRRs can recognize a specific pathogen, thereby activating separate or shared pathways. Generally, the collaboration between PRRs typically results in enhanced transcriptional and cellular responses, i.e. synergistic inflammatory responses, as compared to each PRR. The fact that several receptors may be involved in pathogen recognition renders the system more robust against immune evasion by the pathogenic microbe. Not only can it scale up the inflammatory response, but it may also tailor it to the type of microbe encountered. Importantly, a better understanding of the effective interplay between DC signaling pathways may eventually be exploited in the development of vaccines. Hence, TLRs, RLRs, NLRs, and CLRs can cross talk and synergize to orchestrate immune responses effectively. Cross talks observed between PRRs that belong to the same family, or between different types of PRRs, are detailed below and on the DC map (Figure 2). Additionally, a reduced version of those cross talks is presented in Figure 3.

TLR3/4 synergize with endosomal TLR7-9 to increase the production of Th1- polarizing cytokine IL-12p70 by more than 20-fold compared to either receptor alone; the mechanisms underlying this synergy are not fully understood [37-39]. It is conceivable that activation of IRF transcription factors by dual TLR engagement may enhance IL-12 transcription. Additionally, TLR7 and TLR4 synergize for the production of inflammatory cytokine IL-1 $\beta$ [39]. Napolitani et al. speculated that synergistic TLR stimulation may result from sustained signaling, or possibly imply complementary signaling pathways that have yet to be identified [39]. The cross talk pathways that may contribute to TLR signaling synergy are illustrated in Figure $3 \mathrm{a}$.

TLR3 and RLRs have been shown to be important in recognizing RNA viruses in different cellular compartments. TLR3 is present in endosomal membranes and binds to the dsRNA phagocytosed from viral infected apoptotic cells [40-42]. In contrast, RIG-I/MDA5 functions as a sensor that detects actively replicating viruses in the cytoplasm [43-46]. Although the pathways triggered by TLR3 and RLRs are independent, they converge further downstream and result in the activation of key transcription factors, such as $\mathrm{NF} \kappa \mathrm{B}$, IRF3 and 7, and AP-1 (c-Jun/ATF2), which ultimately induce the expression of IFN $\beta[47,48]$ (Figure 3b). Recently, Perrot and his coworkers reported that concomitant engagement of TLR3 and RLR on myeloid DCs by poly (I:C) dsRNA is required to induce high levels of IL-12 and type I IFN, which in turn lead to an optimal production of IFN $\gamma$ by NK cells [49].

Activation of NF $\kappa \mathrm{B}$ and of the MAPK cascade occurs in the TLR and NLR signaling pathways (for review, see [34]) (Figure 3c). NOD2 agonist, MDP and TLR4 agonist, LPS have a synergistic effect on the production of inflammatory cytokine TNF $\alpha$, which is apparently due to removal of a block in translation of the TNF $\alpha$ mRNA expressed in response to MDP [50]. NOD1 and NOD2 also act in synergy with TLRs 3,4 , and 9 in human DCs to induce IL-12p70 production and promote Th1 cell differentiation [51].

TLR2 and Dectin-1 are synergistic in mediating IL-12 and TNF $\alpha$ production [52] (Figure 3d). Interestingly, Dectin-1 can also promote synthesis of IL-2 and IL-10 in DCs through the recruitment of Syk kinase in response to zymosan, a cell-wall preparation of yeast [53]. Hence, during pathogenic infection, stimuli from either a single antigen or different antigenic components from a single pathogen could activate different PRRs [53]. The final immune response is the combined effect produced through activation of multiple PRRs and cross talks between the signaling pathways activated through these receptors.

\section{Network control and negative regulation of PRR responses}

Appropriate and accurate PRR responses to pathogen signals are essential for the host defense. Yet over-activated cytokine responses to infection can be detrimental to the host. In order to generate an effective but non-toxic response, control mechanisms that negatively regulate the degree and duration of PRR responses are needed. Such surveillance mechanisms operate at different nodes in the PRR-induced signaling cascades. Regulatory mechanisms, which include degradation, sequestration, or inhibition of signaling molecules, are represented schematically in Figure 4. Proteins such as A20, SIKE and PIN1 negatively regulate both TLR and RLR signaling pathways, while others inhibit a specific pathway. For instance, LGP2 interferes with the recognition of viral RNA by RIG-I and MDA5. LGP2 is a RIG-I-like RNA helicase that sequesters dsRNA away from RIG-I. Thus, it acts as a negative regulator of RIG-I signaling. Unlike RIG-I and MDA5, LGP2 lacks the CARD domain required for the interaction with the MAVS adaptor and for signal transduction [54]. 
A20 functions as a feedback negative regulator of the TLR3 pathway by inhibiting TRIF-mediated induction of NFkB and IFN $\beta$ transcription (Figure 4a). It was demonstrated to interact with the adaptor protein TRIF by coimmunoprecipitation experiments, and targets it for degradation [55,56]. Moreover, A20 was shown to restrict TLR-induced TRAF6 ubiquitination, most likely by deconjugating ubiquitin chains onto TRAF6, thereby inhibiting the activation of $\mathrm{NF} \kappa \mathrm{B}$ signaling [57-60]. A20 was also shown to inhibit RIG-I-induced antiviral state, namely gene expression of IRF3, IRF7, and NF $\kappa$ B via its $\mathrm{C}$-terminal ubiquitin ligase domain. According to Lin and collaborators, the inhibitory effect of A20 occurred upstream of the IKKE/TBK1 kinases, yet its biological target had yet to be identified [55]. It is noteworthy that A20 was previously shown to interact with TBK1 and IKKE by co-immunoprecipitation, thereby inhibiting IRF3 phosphorylation and subsequent dimerization; nevertheless, the molecular mechanism involved in this negative regulation by A 20 was not entirely unraveled [61]. RIP1 is a key mediator of TLR3-induced NF $\kappa \mathrm{B}$ activation [62]. Interestingly, A20 downregulates $\mathrm{NF} \kappa \mathrm{B}$ signaling through the cooperativity of its two ubiquitinediting domains: one domain de-ubiquitinates RIP at Lys63, while the other poly-ubiquitinates RIP at Lys48, thereby targeting it for proteasomal degradation [60].

SIKE was demonstrated to associate with IKKE and TBK1 by co-immunoprecipitation (Figure 4b). Overexpression of SIKE inhibits IKKE- and TBK1-mediated antiviral response by disrupting their interaction with signaling components TRIF and IRF3. Indeed, those two kinases play a crucial role in RIG-I- and TLR3-triggered activation of IRF3 [63].

PIN1 is a peptidylprolyl cis-trans isomerase that promotes proteasomal degradation of phosphorylated IRF3 by augmenting its poly-ubiquitination [64] (Figure 4c). RNF125 is a ubiquitin ligase that negatively regulates RIG-I signaling, by targeting RIG-I for proteasomal degradation; likewise, RNF125 conjugates ubiquitin to MDA5 [65] (Figure 4d). NLRX1 is a potent inhibitor of the MAVS-mediated expression of the IFN $\beta$ gene (Figure $4 d$ ). It localizes to the mitochondrial outer membrane and disrupts the interaction between RIG-I and its adaptor MAVS [66].

SOCS proteins inhibit cytokine-mediated signal transduction by targeting JAK/STAT signaling (Figure 4e). Cytokines include various interleukins and IFN $\alpha / \beta / \gamma$. Their transcription is induced by cytokine activity, which qualifies them as inducible feedback inhibitors. SOCS1 and SOCS3 inhibit JAK activity: SOCS1 binds to JAK2 and acts as a pseudo-substrate, while SOCS3 specifically binds to gp130 (signal transducer) cytokine receptors such as the IL-6 receptor (for review, see [67]). A study by Mansell and coll. indicated that
SOCS1 may also poly-ubiquitinate and degrade TIRAP in TLR4 signaling, thereby resulting in an impaired $\mathrm{NF} \kappa \mathrm{B}$ response [68], whereas another report suggested that SOCS1 is part of a ubiquitin ligase complex, which directly interacts with $\mathrm{NF} \kappa \mathrm{B}$ in the nucleus, leading to its ubiquitination and degradation [69]. We chose to solely represent the interaction between SOCS1 and TIRAP. Concerning non-gp130 cytokine receptors like the IFN $\gamma$ receptor, SOCS3 was shown to inhibit STAT1 phosphorylation [70].

Additional negative regulators include IRAK-M and phosphatases. IRAK-M negatively regulates TLR signaling by preventing the dissociation of IRAK1 and IRAK4 from MyD88 and the formation of IRAK1TRAF6 complexes, as revealed by co-transfection experiments into heterologous cells followed by co-immunoprecipitation [71]. The authors proposed that IRAK-M may either inhibit IRAK1 and IRAK4 phosphorylation, or stabilize the TLR-MyD88-IRAK1IRAK4 complex. Phosphatases were shown to be implicated in the regulation of PRR responses. Protein phosphatase 2C (PP2C) was demonstrated to dephosphorylate and thus inactivate TAK1 in vitro, and co-immunoprecipitation experiments indicated the association of PP2C with TAK1 [72,73]. Earlier studies demonstrated that PP2A plays a negative regulatory role in the activation of IKK and NF $\kappa \mathrm{B}$ in response to various cellular stimuli $[74,75]$. However, more recent studies suggested a positive regulatory role, involving a physical interaction between PP2A and IKK [76,77].

\section{Computational motif detection analysis of the DC network}

To identify motifs in our DC signaling network, we used a fully connected directed graph that was reconstructed from our DC map, as described in detail in Additional file 1 , followed by a motif search using several detection methods [78-80]. We employed the FANMOD software [80] to identify motifs of size $3,4,5$ and 6 . Motifs with $\mathrm{z}$-scores $>2$ were considered as significantly overrepresented if obtained with a p-value $<0.005$ in 1000 shuffled networks. No significantly overrepresented motifs of size 3 were detected. Among the significantly overrepresented motifs of size 4, 5 and 6, the bifan and the feedforward motifs were the top most enriched motifs detected (Additional file 2). The rest of the significantly overrepresented motifs contained generalizations of these two types as well as the multi-input convergence (MIC) motif. An example of each motif type is shown in Figure 5. Figure S2 in Additional file 1 illustrates instances of bifan motifs in the entire graph. Similar motifs of node size 5 and 6 were also found (data not shown). We observed that feedback motifs were not enriched in this network. 


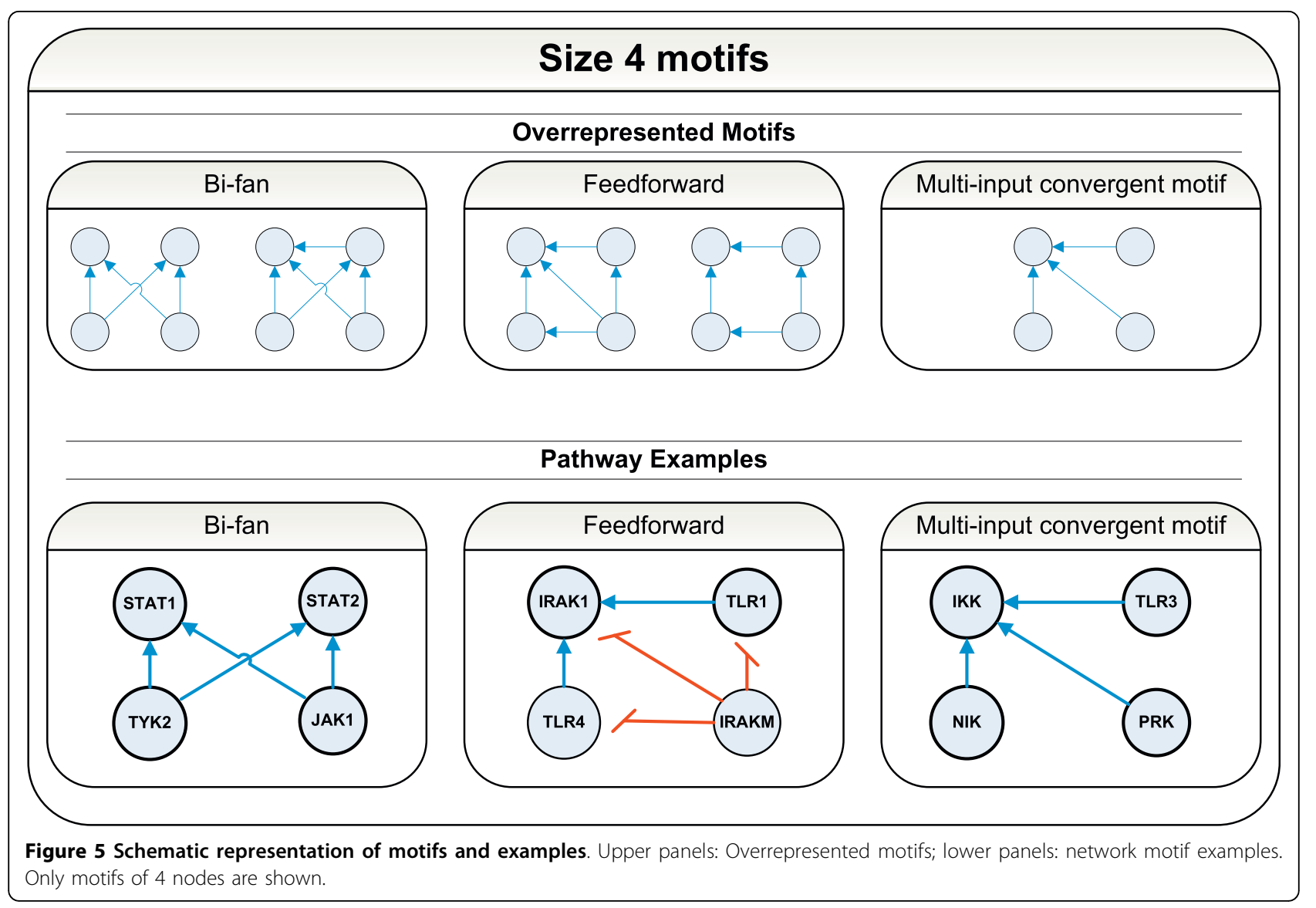

Motifs have been shown to functionally implement signal processing within larger networks $[81,82]$. Obtaining an outline of the regulatory motifs that are part of the DC network may provide further insight into this complex system. Bifan motifs, which support cross talk, and feedforward loops, which favor signal persistency and noise filtering have been shown to be prevalent in biological networks [78,83-85]. Overrepresentation of MIC motifs suggests another control mechanism whereby several routes lead to the regulation of the same target.

\section{Utility \& Discussion}

The DC pathway map is a public knowledgebase that offers a platform for the curation, diffusion, and update of information about the signaling cascades activated upon viral and bacterial infection in DCs. Its manual curation is based on extensive literature searches, and its dissemination relies on the availability of a navigable map of nodes and edges through the internet. Pathway layout has been optimized manually in order to provide more clarity to the diagram. In particular, we have put nodes that interact with one another in close proximity. In the web-published diagram, each node is clickable and links to a complete list of interactions in which it is involved; interactions themselves are supported by hyperlinked PMIDs. Moreover, each node that belongs to either a Protein or RNA category has one or more hyperlinked GeneIDs, and is tied to a wiki page, which lists all interactions in which it is engaged. Wiki pages allow experts to contribute their remarks, suggestions or literature updates. We expect to update the map regularly with new data derived from the literature as well as experts' intellectual contributions on the wiki. Hence, the DC map represents both an online resource and an opportunity for community-wide collaboration. An xml version of the pathway is available for download on the website to allow biologists to modify and expand it in accordance with their own experimental observations. This $\mathrm{xml}$ file (also available as Additional file 3) includes the PMIDs supporting interactions and GeneIDs describing entities.

Recently, Pico et al. created an open platform for the curation of biological pathways referred to as WikiPathways [86]. The use of wiki pages to represent the pathways allows limited access to the knowledgebase and does not support presentation of large networks, in contrast to our approach, which is to use the wiki to facilitate discussion. 
Kitano's group previously created a comprehensive map of macrophage molecular interactions including ligands such as PAMPs and interleukins as input signals, and the release of cytokines and lipids as output signals [87]. In the present work, we included pathogens and PAMPs as inputs, as well as cytokines like IFN $\alpha$ and TNF $\alpha$. As outputs, the induction of inflammatory cytokine expression, such as IL-6 and IL-12 was depicted. In their comprehensive map of TLR signaling, Kitano's group employed a top-down approach to build a model that emphasizes signal convergence [14]. We used a multi-centric approach to build the DC signaling network, beginning with the curation of induction of IFN $\beta$ enhanceosome through activation of the key transcription factors IRF3, NF $\kappa \mathrm{B}$, AP1 upon viral invasion. Parallel signaling shows cross talk at several points and network branches in many directions. In that respect, our approach is similar to that of Raza and coll. [88]. However, we also provide simplified diagrams that illustrate the major cross talk and negative regulatory mechanisms that are part of the DC signaling network. These schematics complement our comprehensive network by extracting the main information and presenting a simpler version of the complex mechanisms taking place in DCs.

This mechanism for generating specific pathways also improves upon the offerings that exist in such repositories as Science's STKE biological pathways database or KEGG. While STKE "pathway authorities" can be reached to with regards to pathway alterations, the process suffers from a lack of transparency and from the review article dilemma of being too biased in specificity or too general in the canonical pathways that may have stagnated in the repository. While repositories like Reactome and KEGG provide output in many usable formats for modelers, they lack transparency and focus despite the inclusion of specific reaction modules.

As we were finalizing this manuscript, a new community-based platform named Payao http://www.payaologue. org was developed by CellDesigner for sharing pathway models. Payao provides a web-based interface for adding tags and comments to curated pathway models. In contrast to our wiki system, it assigns privileges to specific community members [89]. As parallel approaches to the biocuration of pathway models may be taken, the research community is encouraged to share its knowledge and support curators in their efforts to assemble and edit pathway diagrams. The wiki system is robust and reliable in a sense that it keeps track of the changes made by contributors. As biocuration is gradually gaining more recognition, we reckon that our platform as well as others will each play a part in improving community-driven pathway enrichment [90].
With these tools to address the issues of curated network processes for use in modeling, we offer a curated signaling pathway of DCs undergoing viral infection. This pathway does not compare to current complexity and richness of Kitano's Toll-like receptor network [14]. However, manual curation from our community has produced an easily parsable network with the possibility of scaling for unforeseen future applications. The high degree of curation in this network offers a framework for incorporation of private or public experimental data as well as well represented evidence to enhance the validity in modeling. As a community-driven process, we hope that specific networks can rapidly grow and overcome the hurdles of increased data saturation and complexity, while meeting the needs of experimentalists, modelers and computational biologists.

We performed an automated motif detection analysis of the entire DC network. This analysis revealed an over-representation of motifs favoring mechanisms such as cross talk, signaling persistence, and signal convergence. In particular, the families of bifan, feedforward and MIC motifs were enriched. Bifans allow for cross talk between the different regulators and may be an important control mechanism for activating the same pathway by multiple types of triggers. The feedforward loops allow for noise reduction from transient activation of the general regulator and are effective only once there are enough signals to activate the specific regulator [78,83-85]. Finally, the MIC motif also provides another variation of the bifan control mechanism whereby several pathways lead to the regulation of the same target. As DCs need to coordinate signals triggered by various pathogens to produce the specific immune response, the prevalence of bifan, feedforward and MIC motifs may be providing DCs with mechanisms to support their proper function.

\section{Conclusions}

In this report, we present a comprehensive network map of the DC signaling network. Based on a detailed and thorough search of the relevant literature, we manually curated a pathway map of the signaling events triggered upon viral and bacterial infection. In addition to TLRdependent pathways, cascades deriving from CLRs, RLRs and NLRs are depicted. The map is intended to be comprehensive and help researchers to unravel the signal transduction pathway and gene response mechanisms occurring in the DC in response to pathogens. We anticipate updating the map regularly using data drawn from newly published studies, as well as through exchanges with researchers whose area of expertise is cellular and molecular immunology. Those exchanges will be made possible by the availability of a wiki, which 
will let experts suggest corrections or additions through their feedback and comments.

\section{Availability and requirements}

The DC signaling pathway map is accessible at http:// tsb.mssm.edu/pathwayPublisher/DC_pathway/ DC_pathway_index.html.

\section{Additional material}

\section{Additional file 1: Supporting Methods \& Figures S1-S2. This file}

describes the method employed for the computational motif detection analysis of the DC network. It also illustrates examples of motifs identified in the DC network in Figure S1, and instances of bifan motifs found in the entire graph in Figure S2.

Additional file 2: FANMOD size 4 output. This output file, obtained using the FANMOD program, contains all overrepresented motifs of size 4 .

Additional file 3: DC signaling pathway. This file is an $\mathrm{xml}$ version of the DC signaling pathway map, which allows biologists to edit and/or expand it in accordance with their own experimental observations.

\begin{abstract}
Abbreviations
AP-1: activator protein-1; APC: antigen-presenting cell; ATF2: activation transcription factor 2; BioPP: Biological Pathway Publisher; CARD: caspase recruitment domain; CLR: C-Type lectin receptor; CRD: carbohydrate recognition domain; DC, Dendritic cell; dsRNA: double-stranded RNA; IFN: interferon; IKK: I $\kappa \mathrm{B}$ (inhibitor of $\kappa \mathrm{B}$ ) kinase; IL: interleukin; IRAK: IL-1 receptorassociated kinase; IRF: IFN regulatory factor; $\mid \kappa \mathrm{B}$ : inhibitor of $\kappa \mathrm{B}$; KEGG: Kyoto Encyclopedia of Genes and Genomes; LPS: lipopolysaccharide; LRR: leucine rich repeat; MAPK: mitogen-activated protein kinase; MAVS: mitochondrial associated viral stimulator; MDA5: melanoma differentiation associated gene 5; MDP: muramyl dipeptide; MGL: macrophage galactose-type lectin; MHC: major histocompatibility complex; MIC: multi-input convergence; MR: mannose receptor; MyD88: myeloid differentiation primary response gene 88; NALP3: NLR family, pyrin domain containing 3; NF $\kappa$ B: nuclear factor kappa B; NLR: nucleotide-binding oligomerization domain (NOD)-like receptor; NLRX1: NLR family member X1; NOD: nucleotide-binding oligomerization domain; PAMP: pathogen-associated molecular pattern; PIN1: peptidylprolyl cis/trans isomerase, NIMA (never in mitosis gene a)-interacting 1; PMID: PubMed ID; PRR: pattern recognition receptor; RICK: RIP (receptorinteracting protein)-like interacting caspase-like apoptosis regulatory protein kinase; RIG-I: retinoic acid-inducible gene-l; RIP1: receptor interacting protein 1; RLR: RIG--like receptor; RNF125: Ring finger protein 125; SBML: Systems Biology Mark-up Language; SIKE: Suppressor of IKKE; SOCS: suppressor of cytokine signaling; ssRNA: single-stranded RNA; STKE: Signal Transduction Knowledge Environment; SYK: spleen tyrosine kinase; TAK1: transforming growth factor $\beta$-activated kinase 1; TBK1: TANK (TNFR-associated factor family member-associated NFkB activator) binding kinase 1; TIR: Toll/IL-1R; TIRAP: TIR domain-containing adaptor protein; TLR: Toll-like receptor; TNF $\alpha$ : tumor necrosis factor- $\alpha$; TRAM: TRIF-related adaptor molecule; TRIF: TIRcontaining adaptor inducing IFN $\beta$.
\end{abstract}

\section{Acknowledgements}

This project was supported by NIH NIAID Contract No. HHSN2662000500021C. We thank Dr. Ganesh Viswanathan for his collaboration in the original BioPP software development. We thank Dr. Yishai Shimoni for valuable discussions.

\section{Author details}

${ }^{1}$ Center for Translational Systems Biology and Department of Neurology, Mount Sinai School of Medicine, New York, NY 10029, USA. ${ }^{2}$ Computational Biology Program, Courant Institute, New York University, New York, NY 10012, USA.

\section{Authors' contributions}

SP was the initial curator and wrote the first manuscript draft. HP is the present curator and revised the manuscript. JS contributed to the curation, figure design and manuscript preparation. GN maintained and revised the custom software suite utilized for web-publishing. GN conceived and designed the network motif analysis. IN and GN performed the network motif analysis and participated in the manuscript writing. SCS organized and directed the project and revised the manuscript. All authors read and approved the final version.

Received: 4 May 2010 Accepted: 7 October 2010 Published: 7 October 2010

\section{References}

1. Caux C, Massacrier C, Vanbervliet B, Dubois B, Durand I, Cella M, Lanzavecchia A, Banchereau J: CD34+ hematopoietic progenitors from human cord blood differentiate along two independent dendritic cell pathways in response to granulocyte-macrophage colony-stimulating factor plus tumor necrosis factor alpha: II. Functional analysis. Blood 1997, 90:1458-1470.

2. Jego G, Palucka AK, Blanck JP, Chalouni C, Pascual V, Banchereau J: Plasmacytoid dendritic cells induce plasma cell differentiation through type I interferon and interleukin 6. Immunity 2003, 19:225-234.

3. Reis e Sousa C: Activation of dendritic cells: translating innate into adaptive immunity. Curr Opin Immunol 2004, 16:21-25.

4. Clark GJ, Angel N, Kato M, Lopez JA, MacDonald K, Vuckovic S, Hart DN: The role of dendritic cells in the innate immune system. Microbes Infect 2000, 2:257-272

5. Brown GD, Taylor PR, Reid DM, Willment JA, Williams DL, MartinezPomares L, Wong SY, Gordon S: Dectin-1 is a major beta-glucan receptor on macrophages. J Exp Med 2002, 196:407-412.

6. Geijtenbeek TB, Krooshoop DJ, Bleijs DA, van Vliet SJ, van Duijnhoven GC, Grabovsky V, Alon R, Figdor CG, van Kooyk Y: DC-SIGN-ICAM-2 interaction mediates dendritic cell trafficking. Nat Immunol 2000, 1:353-357.

7. Maeda S, Hsu LC, Liu H, Bankston LA, limura M, Kagnoff MF, Eckmann L, Karin M: Nod2 mutation in Crohn's disease potentiates NF-kappaB activity and IL-1 beta processing. Science 2005, 307:734-738.

8. Macagno A, Napolitani G, Lanzavecchia A, Sallusto F: Duration, combination and timing: the signal integration model of dendritic cell activation. Trends Immunol 2007, 28:227-233.

9. Murray PJ: The JAK-STAT signaling pathway: input and output integration. J Immunol 2007, 178:2623-2629.

10. Nestle FO, Banchereau J, Hart D: Dendritic cells: On the move from bench to bedside. Nat Med 2001, 7:761-765.

11. Kitano H, Funahashi A, Matsuoka $Y$, Oda K: Using process diagrams for the graphical representation of biological networks. Nat Biotechnol 2005, 23:961-966.

12. Ogata H, Goto S, Sato K, Fujibuchi W, Bono H, Kanehisa M: KEGG: Kyoto Encyclopedia of Genes and Genomes. Nucleic Acids Res 1999, 27:29-34.

13. Vastrik I, D'Eustachio P, Schmidt E, Gopinath G, Croft D, de Bono B, Gillespie M, Jassal B, Lewis S, Matthews L, et al: Reactome: a knowledge base of biologic pathways and processes. Genome Biol 2007, 8:R39.

14. Oda $\mathrm{K}$, Kitano $\mathrm{H}$ : A comprehensive map of the toll-like receptor signaling network. Mol Syst Biol 2006, 2:2006 0015.

15. Funahashi A, Tanimura N, Morohashi M, Kitano H: CellDesigner: a process diagram editor for gene-regulatory and biochemical networks. BioSilico 2003, 1:159-162

16. Viswanathan GA, Nudelman G, Patil S, Sealfon SC: BioPP: a tool for webpublication of biological networks. BMC Bioinformatics 2007, 8:168.

17. Lee MS, Kim YJ: Signaling pathways downstream of pattern-recognition receptors and their cross talk. Annu Rev Biochem 2007, 76:447-480.

18. Akira S, Uematsu S, Takeuchi O: Pathogen recognition and innate immunity. Cell 2006, 124:783-801.

19. Dunne A, Ejdeback M, Ludidi PL, O'Neill LA, Gay NJ: Structural complementarity of Toll/interleukin-1 receptor domains in Toll-like receptors and the adaptors Mal and MyD88. J Biol Chem 2003, 278:41443-41451. 
20. Fitzgerald KA, Rowe DC, Barnes BJ, Caffrey DR, Visintin A, Latz E, Monks B, Pitha PM, Golenbock DT: LPS-TLR4 signaling to IRF-3/7 and NF-kappaB involves the toll adapters TRAM and TRIF. J Exp Med 2003, 198:1043-1055.

21. Horng T, Barton GM, Flavell RA, Medzhitov R: The adaptor molecule TIRAP provides signalling specificity for Toll-like receptors. Nature 2002, 420:329-333.

22. Horng T, Barton GM, Medzhitov R: TIRAP: an adapter molecule in the Toll signaling pathway. Nat Immunol 2001, 2:835-841.

23. Oshiumi H, Matsumoto M, Funami $K$, Akazawa T, Seya T: TICAM-1, an adaptor molecule that participates in Toll-like receptor 3-mediated interferon-beta induction. Nat Immunol 2003, 4:161-167.

24. Yamamoto M, Sato S, Hemmi H, Sanjo H, Uematsu S, Kaisho T, Hoshino K, Takeuchi O, Kobayashi M, Fujita T, et al: Essential role for TIRAP in activation of the signalling cascade shared by TLR2 and TLR4. Nature 2002, 420:324-329.

25. Henneke P, Morath S, Uematsu S, Weichert S, Pfitzenmaier M, Takeuchi O, Muller A, Poyart C, Akira S, Berner R, et al: Role of lipoteichoic acid in the phagocyte response to group B streptococcus. J Immunol 2005, 174:6449-6455.

26. Netea MG, van de Veerdonk F, Verschueren I, van der Meer JW, Kullberg BJ: Role of TLR1 and TLR6 in the host defense against disseminated candidiasis. FEMS Immunol Med Microbiol 2008, 52:118-123.

27. Hemmi H, Takeuchi O, Sato S, Yamamoto M, Kaisho T, Sanjo H, Kawai T, Hoshino K, Takeda K, Akira S: The roles of two IkappaB kinase-related kinases in lipopolysaccharide and double stranded RNA signaling and viral infection. J Exp Med 2004, 199:1641-1650.

28. Medzhitov R, Preston-Hurlburt P, Kopp E, Stadlen A, Chen C, Ghosh S, Janeway CA Jr: MyD88 is an adaptor protein in the $\mathrm{hToll} / \mathrm{IL}-1$ receptor family signaling pathways. Mol Cell 1998, 2:253-258.

29. Kawai T, Takahashi K, Sato S, Coban C, Kumar H, Kato H, Ishii KJ, Takeuchi O, Akira S: IPS-1, an adaptor triggering RIG-I- and Mda5-mediated type I interferon induction. Nat Immunol 2005, 6:981-988.

30. Seth RB, Sun L, Ea CK, Chen ZJ: Identification and characterization of MAVS, a mitochondrial antiviral signaling protein that activates NFkappaB and IRF 3. Cell 2005, 122:669-682.

31. Lin R, Lacoste J, Nakhaei $P$, Sun $Q$, Yang L, Paz S, Wilkinson P, Julkunen I, Vitour D, Meurs E, Hiscott J: Dissociation of a MAVS/IPS-1/VISA/CardifIKKepsilon molecular complex from the mitochondrial outer membrane by hepatitis C virus NS3-4A proteolytic cleavage. J Virol 2006, 80:6072-6083.

32. van Vliet SJ, Garcia-Vallejo JJ, van Kooyk Y: Dendritic cells and C-type lectin receptors: coupling innate to adaptive immune responses. Immunol Cell Biol 2008, 86:580-587.

33. Brown GD: Dectin-1: a signalling non-TLR pattern-recognition receptor. Nat Rev Immunol 2006, 6:33-43.

34. Kawai T, Akira S: The roles of TLRs, RLRs and NLRs in pathogen recognition. Int Immunol 2009, 21:317-337.

35. Kumagai $Y$, Takeuchi O, Akira S: Pathogen recognition by innate receptors. J Infect Chemother 2008, 14:86-92.

36. Martinon F, Tschopp J: Inflammatory caspases: linking an intracellular innate immune system to autoinflammatory diseases. Cell 2004, 117:561-574.

37. Bekeredjian-Ding I, Roth SI, Gilles S, Giese T, Ablasser A, Hornung V, Endres S, Hartmann G: T cell-independent, TLR-induced IL-12p70 production in primary human monocytes. J Immunol 2006, 176:7438-7446.

38. Gautier G, Humbert M, Deauvieau F, Scuiller M, Hiscott J, Bates EE, Trinchieri G, Caux C, Garrone P: A type I interferon autocrine-paracrine loop is involved in Toll-like receptor-induced interleukin-12p70 secretion by dendritic cells. J Exp Med 2005, 201:1435-1446.

39. Napolitani G, Rinaldi A, Bertoni F, Sallusto F, Lanzavecchia A: Selected Tolllike receptor agonist combinations synergistically trigger a $T$ helper type 1-polarizing program in dendritic cells. Nat Immunol 2005, 6:769-776.

40. Alexopoulou L, Holt AC, Medzhitov R, Flavell RA: Recognition of doublestranded RNA and activation of NF-kappaB by Toll-like receptor 3. Nature 2001, 413:732-738

41. de Bouteiller O, Merck E, Hasan UA, Hubac S, Benguigui B, Trinchieri G, Bates EE, Caux C: Recognition of double-stranded RNA by human toll-like receptor 3 and downstream receptor signaling requires multimerization and an acidic pH. J Biol Chem 2005, 280:38133-38145.
42. Jiang Z, Mak TW, Sen G, Li X: Toll-like receptor 3-mediated activation of NF-kappaB and IRF3 diverges at Toll-IL-1 receptor domain-containing adapter inducing IFN-beta. Proc Natl Acad Sci USA 2004, 101:3533-3538.

43. Andrejeva J, Childs KS, Young DF, Carlos TS, Stock N, Goodbourn S, Randall RE: The V proteins of paramyxoviruses bind the IFN-inducible RNA helicase, mda-5, and inhibit its activation of the IFN-beta promoter. Proc Natl Acad Sci USA 2004, 101:17264-17269.

44. Kang DC, Gopalkrishnan RV, Wu Q, Jankowsky E, Pyle AM, Fisher PB: mda-5: An interferon-inducible putative RNA helicase with double-stranded RNA-dependent ATPase activity and melanoma growth-suppressive properties. Proc Natl Acad Sci USA 2002, 99:637-642.

45. Yoneyama M, Kikuchi M, Matsumoto K, Imaizumi T, Miyagishi M, Taira K, Foy E, Loo YM, Gale M Jr, Akira $S$, et al: Shared and unique functions of the DExD/H-box helicases RIG-I, MDA5, and LGP2 in antiviral innate immunity. J Immunol 2005, 175:2851-2858.

46. Yoneyama M, Kikuchi M, Natsukawa T, Shinobu N, Imaizumi T, Miyagishi M, Taira K, Akira S, Fujita T: The RNA helicase RIG-I has an essential function in double-stranded RNA-induced innate antiviral responses. Nat Immunol 2004, 5:730-737.

47. Kim T, Kim TY, Lee WG, Yim J, Kim TK: Signaling pathways to the assembly of an interferon-beta enhanceosome. Chemical genetic studies with a small molecule. J Biol Chem 2000, 275:16910-16917.

48. Kawai T, Akira S: Innate immune recognition of viral infection. Nat Immunol 2006, 7:131-137.

49. Perrot I, Deauvieau F, Massacrier C, Hughes N, Garrone P, Durand I, Demaria O, Viaud N, Gauthier L, Blery M, et al: TLR3 and Rig-like receptor on myeloid dendritic cells and Rig-like receptor on human NK cells are both mandatory for production of IFN-gamma in response to doublestranded RNA. J Immunol 2010, 185:2080-2088.

50. Wolfert MA, Murray TF, Boons GJ, Moore JN: The origin of the synergistic effect of muramyl dipeptide with endotoxin and peptidoglycan. J Biol Chem 2002, 277:39179-39186.

51. Tada H, Aiba S, Shibata K, Ohteki T, Takada H: Synergistic effect of Nod1 and Nod2 agonists with toll-like receptor agonists on human dendritic cells to generate interleukin-12 and T helper type 1 cells. Infect Immun 2005, 73:7967-7976.

52. Gantner BN, Simmons RM, Canavera SJ, Akira S, Underhill DM: Collaborative induction of inflammatory responses by dectin-1 and Toll-like receptor 2. J Exp Med 2003, 197:1107-1117.

53. Rogers NC, Slack EC, Edwards AD, Nolte MA, Schulz O, Schweighoffer E, Williams DL, Gordon S, Tybulewicz VL, Brown GD, Reis e Sousa C: Sykdependent cytokine induction by Dectin-1 reveals a novel pattern recognition pathway for $C$ type lectins. Immunity 2005, 22:507-517.

54. Rothenfusser S, Goutagny N, DiPerna G, Gong M, Monks BG, Schoenemeyer A, Yamamoto M, Akira S, Fitzgerald KA: The RNA helicase Lgp2 inhibits TLR-independent sensing of viral replication by retinoic acid-inducible gene-I. J Immunol 2005, 175:5260-5268.

55. Lin R, Yang L, Nakhaei P, Sun Q, Sharif-Askari E, Julkunen I, Hiscott J: Negative regulation of the retinoic acid-inducible gene l-induced antiviral state by the ubiquitin-editing protein A20. J Biol Chem 2006, 281:2095-2103.

56. Wang YY, Li L, Han KJ, Zhai Z, Shu HB: A20 is a potent inhibitor of TLR3and Sendai virus-induced activation of NF-kappaB and ISRE and IFNbeta promoter. FEBS Lett 2004, 576:86-90.

57. Boone DL, Turer EE, Lee EG, Ahmad RC, Wheeler MT, Tsui C, Hurley P, Chien $M$, Chai $S$, Hitotsumatsu $O$, et al: The ubiquitin-modifying enzyme A20 is required for termination of Toll-like receptor responses. Nat Immunol 2004, 5:1052-1060.

58. Deng L, Wang C, Spencer E, Yang L, Braun A, You J, Slaughter C, Pickart C, Chen ZJ: Activation of the IkappaB kinase complex by TRAF6 requires $a$ dimeric ubiquitin-conjugating enzyme complex and a unique polyubiquitin chain. Cell 2000, 103:351-361.

59. Turer EE, Tavares RM, Mortier E, Hitotsumatsu O, Advincula R, Lee B, Shifrin N, Malynn BA, Ma A: Homeostatic MyD88-dependent signals cause lethal inflamMation in the absence of A20. J Exp Med 2008, 205:451-464.

60. Wertz IE, O'Rourke KM, Zhou H, Eby M, Aravind L, Seshagiri S, Wu P, Wiesmann C, Baker R, Boone DL, et al: De-ubiquitination and ubiquitin ligase domains of A20 downregulate NF-kappaB signalling. Nature 2004, 430:694-699. 
61. Saitoh T, Yamamoto M, Miyagishi M, Taira K, Nakanishi M, Fujita T, Akira S, Yamamoto N, Yamaoka S: A20 is a negative regulator of IFN regulatory factor 3 signaling. J Immunol 2005, 174:1507-1512.

62. Meylan E, Burns K, Hofmann K, Blancheteau V, Martinon F, Kelliher M, Tschopp J: RIP1 is an essential mediator of Toll-like receptor 3-induced NF-kappa B activation. Nat Immunol 2004, 5:503-507.

63. Huang J, Liu T, Xu LG, Chen D, Zhai Z, Shu HB: SIKE is an IKK epsilon/ TBK1-associated suppressor of TLR3- and virus-triggered IRF-3 activation pathways. EMBO J 2005, 24:4018-4028.

64. Saitoh T, Tun-Kyi A, Ryo A, Yamamoto M, Finn G, Fujita T, Akira S, Yamamoto N, Lu KP, Yamaoka S: Negative regulation of interferonregulatory factor 3-dependent innate antiviral response by the prolyl isomerase Pin1. Nat Immunol 2006, 7:598-605.

65. Arimoto K, Takahashi H, Hishiki T, Konishi H, Fujita T, Shimotohno K: Negative regulation of the RIG-I signaling by the ubiquitin ligase RNF125. Proc Natl Acad Sci USA 2007, 104:7500-7505.

66. Moore CB, Bergstralh DT, Duncan JA, Lei Y, Morrison TE, Zimmermann AG, Accavitti-Loper MA, Madden VJ, Sun L, Ye Z, et al: NLRX1 is a regulator of mitochondrial antiviral immunity. Nature 2008, 451:573-577.

67. Dalpke A, Heeg K, Bartz H, Baetz A: Regulation of innate immunity by suppressor of cytokine signaling (SOCS) proteins. Immunobiology 2008, 213:225-235

68. Mansell A, Smith R, Doyle SL, Gray P, Fenner JE, Crack PJ, Nicholson SE, Hilton DJ, O'Neill LA, Hertzog PJ: Suppressor of cytokine signaling 1 negatively regulates Toll-like receptor signaling by mediating Mal degradation. Nat Immunol 2006, 7:148-155.

69. Maine GN, Mao X, Komarck CM, Burstein E: COMMD1 promotes the ubiquitination of NF-kappaB subunits through a cullin-containing ubiquitin ligase. EMBO J 2007, 26:436-447.

70. Song MM, Shuai K: The suppressor of cytokine signaling (SOCS) 1 and SOCS3 but not SOCS2 proteins inhibit interferon-mediated antiviral and antiproliferative activities. J Biol Chem 1998, 273:35056-35062.

71. Kobayashi K, Hernandez LD, Galan JE, Janeway CA Jr, Medzhitov R, Flavell RA: IRAK-M is a negative regulator of Toll-like receptor signaling. Cell 2002, 110:191-202.

72. Hanada M, Ninomiya-Tsuji J, Komaki K, Ohnishi M, Katsura K, Kanamaru R, Matsumoto K, Tamura S: Regulation of the TAK1 signaling pathway by protein phosphatase 2C. J Biol Chem 2001, 276:5753-5759.

73. Li MG, Katsura K, Nomiyama H, Komaki K, Ninomiya-Tsuji J, Matsumoto K, Kobayashi T, Tamura S: Regulation of the interleukin-1-induced signaling pathways by a novel member of the protein phosphatase $2 \mathrm{C}$ family (PP2Cepsilon). J Biol Chem 2003, 278:12013-12021.

74. DiDonato JA, Hayakawa M, Rothwarf DM, Zandi E, Karin M: A cytokineresponsive IkappaB kinase that activates the transcription factor NFkappaB. Nature 1997, 388:548-554.

75. Sun SC, Maggirwar SB, Harhaj E: Activation of NF-kappa B by phosphatase inhibitors involves the phosphorylation of I kappa B alpha at phosphatase 2A-sensitive sites. J Biol Chem 1995, 270:18347-18351.

76. Kray AE, Carter RS, Pennington KN, Gomez RJ, Sanders LE, Llanes JM, Khan WN, Ballard DW, Wadzinski BE: Positive regulation of IkappaB kinase signaling by protein serine/threonine phosphatase 2A. J Biol Chem 2005, 280:35974-35982.

77. Li S, Wang L, Berman MA, Zhang Y, Dorf ME: RNAi screen in mouse astrocytes identifies phosphatases that regulate NF-kappaB signaling. Mol Cell 2006, 24:497-509.

78. Kashtan N, Itzkovitz S, Milo R, Alon U: Efficient sampling algorithm for estimating subgraph concentrations and detecting network motifs. Bioinformatics 2004, 20:1746-1758.

79. Schreiber F, Schwobbermeyer H: MAVisto: a tool for the exploration of network motifs. Bioinformatics 2005, 21:3572-3574

80. Wernicke S, Rasche F: FANMOD: a tool for fast network motif detection. Bioinformatics 2006, 22:1152-1153.

81. Mangan S, Alon U: Structure and function of the feed-forward loop network motif. Proc Natl Acad Sci USA 2003, 100:11980-11985.

82. Mangan S, Zaslaver A, Alon U: The coherent feedforward loop serves as a sign-sensitive delay element in transcription networks. J Mol Biol 2003, 334:197-204.

83. Alon U: Network motifs: theory and experimental approaches. Nat Rev Genet 2007, 8:450-461.

84. Schreiber BHJaF, (Ed.): Analysis of Biological Networks. Hoboken: Wiley 2008.
85. Shen-Orr SS, Milo R, Mangan S, Alon U: Network motifs in the transcriptional regulation network of Escherichia coli. Nat Genet 2002, 31:64-68.

86. Pico AR, Kelder T, van lersel MP, Hanspers $K$, Conklin BR, Evelo C: WikiPathways: pathway editing for the people. PLOS Biol 2008, 6:e184.

87. Oda K, Kimura T, Matsuoka Y, Funahashi A, Muramatsu M, Kitano H: Molecular Interaction Map of a Macrophage. AfCS Research Reports 2004 2.

88. Raza S, McDerment N, Lacaze PA, Robertson K, Watterson S, Chen Y, Chisholm M, Eleftheriadis G, Monk S, O'Sullivan M, et al: Construction of a large scale integrated map of macrophage pathogen recognition and effector systems. BMC Syst Biol 4:63.

89. Matsuoka Y, Ghosh S, Kikuchi N, Kitano H: Payao: A Community Platform for SBML Pathway Model Curation. Bioinformatics 2010, 26(10):1381-3.

90. Bateman A: Curators of the world unite: the International Society of Biocuration. Bioinformatics 26:991.

doi:10.1186/1752-0509-4-137

Cite this article as: Patil et al:: Signaling network of dendritic cells in response to pathogens: a community-input supported knowledgebase. BMC Systems Biology 2010 4:137.

\section{Submit your next manuscript to BioMed Central and take full advantage of:}

- Convenient online submission

- Thorough peer review

- No space constraints or color figure charges

- Immediate publication on acceptance

- Inclusion in PubMed, CAS, Scopus and Google Scholar

- Research which is freely available for redistribution

Submit your manuscript at www.biomedcentral.com/submit
C Biomed Central 